\title{
Activator Protein-2 $\beta$ Promotes Tumor Growth and Predicts Poor Prognosis in Breast Cancer
}

\author{
Zhenglin Li ${ }^{\mathrm{a}, \mathrm{f}}$ Xiangdong $\mathrm{Xu}^{\mathrm{c}}$ Meihua Luo ${ }^{\mathrm{d}}$ Jiaojiao Hao ${ }^{\mathrm{a}}$ Shilei Zhao \\ Wendan $\mathrm{Yu}^{\mathrm{a}}$ Xiangsheng Xiao ${ }^{\mathrm{b}}$ Jiali Wu ${ }^{\mathrm{b}}$ Fufu Zheng ${ }^{\mathrm{c}}$ Miao Chen ${ }^{\mathrm{b}}$ Yizhuo $\mathrm{Li}^{\mathrm{b}}$ \\ Ge Qin ${ }^{b} \quad Y_{i n a} L_{i a o^{a}} \quad$ Xinrui Zhao ${ }^{a}$ Xinfa Yu ${ }^{d}$ Wei Guo ${ }^{a}$ Lijuan Zou \\ Wuguo Denga,b
}

aInstitute of Cancer Stem Cell \& The Second Affiliated Hospital, Dalian Medical University, Dalian, 'bSun Yat-sen University Cancer Center, State Key Laboratory of Oncology in South China, Collaborative Innovation Center of Cancer Medicine, Guangzhou, 'Department of Thyroid and Breast Surgery, The First Affiliated Hospital of Sun Yat-sen University, Guangzhou, dShunde Hospital of Southern Medical

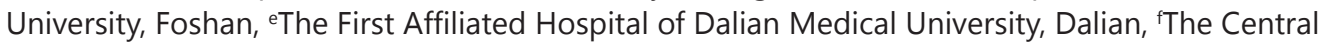
Hospital of Dalian, Dalian, China

\section{Key Words}

Ap- $2 \beta \cdot$ Breast cancer $\cdot$ Prognosis

\begin{abstract}
Background/Aims: Activator protein-2 (AP-2) transcription factors have been proved to be essential in maintaining cellular homeostasis and regulating the transformation from normal growth to neoplasia. However, the role of AP- $2 \beta$, a key member of AP- 2 family, in breast cancer is rarely reported. Methods: The effect of AP- $2 \beta$ on cell growth, migration and invasion in breast cancer cells were measured by MTT, colony formation, wound-healing and transwell assays, respectively. The expression levels of AP- $2 \beta$ and other specific markers in breast cancer cell lines and tissue microarrays from the patients were detected using RT-PCR, Western blot and immunohistochemical staining. The regulation of AP- $2 \beta$ on tumor growth in vivo was analyzed in a mouse xenograft model. Results: We demonstrated the tumor-promoting function of AP- $2 \beta$ in breast cancer. AP- $2 \beta$ was found to be highly expressed in breast cancer cell lines and tumor tissues of breast cancer patients. The shRNA-mediated silencing of AP$2 \beta$ led to the dramatic inhibition of cell proliferation, colony formation ability, migration and invasiveness in breast cancer cells accompanied by the down-regulated expression of some key proteins involved in cancer progression, including p75, MMP-2, MMP-9, C-Jun, p-ERK and STAT3. Overexpression of AP-2 $\beta$ markedly up-regulated the levels of these proteins. Consistent with the in vitro study, the silencing or overexpression of AP- $2 \beta$ blocked or promoted tumor growth in the mice with xenografts of breast cancers. Notably, the high AP-2 $\beta$ expression levels
\end{abstract}

Z. Li, X. Xu, M. Luo and J. Hao contributed equally to this article

Wei Guo, Lijuan Zou

and Wuguo Deng
Dalian Medical University, Dalian; The Second Affiliated Hospital of Dalian Medica

University, Dalian; Sun Yat-sen University Cancer Center, Guangzhou (China)

E-Mail wei1015@dmu.edu.cn; zoulijuan1963@sina.com; dengwg@sysucc.org.cn 
was correlated with poor prognosis and advanced malignancy in patients with breast cancer. Conclusions: Our study demonstrates that AP- $2 \beta$ promotes tumor growth and predicts poor prognosis, and may represent a potential therapeutic target for breast cancer.

(C) 2018 The Author(s)

Published by S. Karger AG, Basel

\section{Introduction}

As the most commonly diagnosed cancer type among women, breast cancer forms a major threat to women's health globally [1-4]. It is mainly divided into the following four molecular subtypes, luminal A, luminal B, basal-like/triple negative, and HER2 [5]. The former two subtypes display high expression of estrogen receptor (ER) and progesterone receptor (PR) and changed level of HER2. Basal-like subtype displays negative expression of ER, PR and HER2, and the patients with this subtype usually owns poor prognosis. HER2 subtype displays negative expression of ER, PR and high expression of HER2 and other genes associated with proliferation. With the continuous progress of research, a new breast cancer subtype, low claudin, was identified. It similarly displays negative expression of ER, PR and HER2, but owns low ki67 expression and high expression of genes involved in EMT [6]. Although progresses have been made in understanding breast cancer biology, the molecular mechanisms associated with proliferative regulation of breast cancer cells, the acquisition of invasion and metastasis phenotype, and the development of therapeutic assistance were still poorly understood. Thus, considering the high complexity and variability in breast cancer development, the discovery and identification of new breast cancer biomarkers and therapeutic targets and the mention and application of new therapeutic strategies based on this seems more significant.

Activator protein-2 (AP-2) transcription factor family, composed of five members, AP$2 \alpha, \mathrm{AP}-2 \beta, \mathrm{AP}-2 \delta, \mathrm{AP}-2 \varepsilon$ and $\mathrm{AP}-2 \gamma$, is involved in the regulation of many biological functions, such as cell proliferation, differentiation, apoptosis and carcinogenesis [7-10]. The aberrant AP-2 activity was uncovered in malignant transformation. AP- $2 \alpha$ has been suggested to function as a tumor suppressor in many cancers, including melanoma, prostate cancer, ovarian cancer, and gliomas [11-14]. By contrast, AP- $2 \gamma$ seems to be an oncogene in testicular and germ cell malignancies $[15,16]$ and is up-regulated in advanced-stage ovarian cancer [17]. Despite of increased studies of AP-2 activity in malignancies, the knowledge of AP-2 expression in these tissues, especially for AP- $2 \beta, \mathrm{AP}-2 \varepsilon$ and AP- $2 \gamma$, is still poorly known. In breast cancer progression, the nuclear expressions of AP- $2 \alpha$ and AP- $2 \alpha / \beta$ were significantly reduced in invasive carcinomas compared to ductal carcinoma in situ [18], and the trend between low nuclear AP- $2 \alpha / \beta$ expression and poor differentiation was also reported [19]. However, the study concerning AP-2 $\beta$ expression alone in breast cancer is so limited. Only one study based on cDNA microarray demonstrated the high expression of AP- $2 \beta$ in lobular breast tumor samples compared to ductal carcinomas [20]. Combined with the previous reports indicating AP- $2 \beta$ functionalized as oncogene to activate human telomerase reverses transcriptase and to up-regulate the transcription of the CRYAB gene through stabilizing p53 $[21,22]$, most likely, we hypothesize the similarly tumorigenic role of AP- $2 \beta$ in breast cancer development, especially in advanced breast cancer.

Here, we reported the elevated expression of AP- $2 \beta$ in breast cancer cells and tissue specimens. Its knockdown in breast cancer cells caused significant inhibition of cell proliferative capability, colony formative ability, migration and invasion accompanied by the down-regulated expression of key proteins involved in cancer progression, such as p75, MMP-2, MMP-9, C-Jun, p-ERK and STAT3. Furthermore, consistent with the in vitro results, silencing of AP- $2 \beta$ blocked tumor growth in mouse model with xenografts of breast cancer, and inversely, its overexpression markedly promoted tumor development. We also showed that the high expression of AP- $2 \beta$ predicted poor prognosis and advanced malignancy in patients with breast cancer. Our results indicate that AP- $2 \beta$ plays a tumor-promoting effect in the progression of breast cancer, especially in high malignant breast cancer, and may serve as a candidate therapeutic target in breast cancer treatment.

\section{KARGER}




\section{Cellular Physiology Cell Physiol Biochem 2018;47:1925-1935 and Biochemistry Published online: July 03, $2018 \quad$\begin{tabular}{l|l} 
DOI: 10.1159/000491463 2018 The Author(s). Published by S. Karger AG, Basel \\
www.karger.com/cpb
\end{tabular} \\ Li et al.: Activator Protein-2 $\beta$ Promotes Tumor Growth}

\section{Materials and Methods}

\section{Cell culture}

Human breast cancer cell lines (MDA-MB-231, T47D, MCF-7 and BT-549) were obtained from American Type Culture Collection (Manassas, VA). Cells were grown in different medium (Leibovitz's L-15 medium, RPMI-1640 medium or Eagle's minimum) supplemented with 10\% fetal bovine serum and the appropriate amount of insulin according to the recommendation and maintained at $37^{\circ} \mathrm{C}$ in a humidified atmosphere containing $5 \% \mathrm{CO}_{2}$.

\section{Western Blot Analysis}

Proteins were separated by SDS-PAGE, transferred to PVDF membrane and immunoblotted respectively with antibodies against AP-2 $\beta$ (SANTA CRUZ), p75(Abcam), MMP9(CST), MMP2(CST), C-jun(CST), Erk(CST), p-Erk(CST), STAT3(CST), and GAPDH (proteintech). Immunoreactive protein bands were detected using ECL(Electro-Chemi-Luminescence) substrates.

\section{Immunohistochemistry staining}

Human tissue microarrays were purchased from Shanghai Outdo Biotech (Shanghai, China). The slides were heated at $65^{\circ} \mathrm{C}$ for $30 \mathrm{~min}$, followed by paraffin removal with xylene and subsequent rehydration with ethanol. Antigen retrieval was performed in citrate buffer $(\mathrm{pH} \mathrm{6.0)}$ maintained at a sub-boiling temperature for 20 mins. Samples were blocked with $10 \%$ goat serum for $1 \mathrm{~h}$ each at RT and incubated with AP- $2 \beta$ antibody (1:100) overnight at $4^{\circ} \mathrm{C}$. The slides were visualized using streptavidin peroxidase IHC assay kit (ZSGB-bio, China) and counterstained with hematoxylin. Slides were evaluated by two pulmonary pathologists using a blind protocol design. For each specimen, the IHC staining score was calculated as intensity expression (negative, no yellow, 0 points; weak, light yellow, 1 points; moderate, yellow brown, 2 points; and strong, brown, 3 points) multiplying with percentage of positive cells (positive cells as $\leq 25 \%$ of the cells, 1 points; $26 \%-50 \%, 2$ points; $51 \%-75 \%, 3$ points; $75 \%$, 4 points) at high-power fields ( $\mathrm{x} 400$ ). Three representative visual fields of each specimen were scored, and the averaged score was used as the final overall assessed score. We defined samples as low expression when the score was $\leq 2$ point, otherwise as high expression.

\section{Transient transfection}

The shRNAs targeting AP-2 $\beta$ (siRNA1: 5'GGUCACCUGUUACAAGUGUTT-3'; 5'-ACACUUGUAACAGGUGACCTT-3'. SIRNA2:5'-CAUGCACCC UCGAUUUGAATT-3'; 5'-UUCAAAUCGAGGGUGUAUGTT-3') and negative control shRNA (5'-UUCUCCGAACGUGUCACGUTT-3'; 5'-ACGUGACACGUUCGGAGAATT-3') were purchased from Shanghai GenePharmaCo (Shanghai, China). The overexpressing plasmids of AP-2 $\beta$ were constructed by our lab before. Cells plated in 96 -well plates (5, 000 cells/well) or six-well plates (200, 000 cells/well) were transfected with shRNAs or overexpressing plasmids (0.05-0.1 $\mathrm{g}$ or 1-2 $\mu \mathrm{g}$ ) encapsulated by lipofactamine 2000. 48 or 72 hours after transfection, protein expression, cell viability and other biological functions were tested respectively.

\section{Cell viability assay}

Cell viability was determined using MTT assay according to the routine protocol.

\section{Colony formation assay}

Cells plated in 6-well plates overnight were transfected with control or AP-2 $\beta$ specific shRNAs for $48 \mathrm{hrs}$. The cells were then trypsinized into single cells and seeded into a 6-well plate at 1000 cells/ well with continuous incubation for 2 weeks. The cells were washed and then fixed with the mixture (methanol:glacial:acetic 1:1:8) for 10 mins, and stained with $0.1 \%$ crystal violet for 30 mins. The clones formed were counted under an optical microscope.

\section{Migration study}

Cells plated in 6-well plate and grown to nearly 70-80\% confluence were transfected with control or AP- $2 \beta$ specific shRNAs for 24 hours and then scraped in a straight line to create a "scratch". After continuous 24 hours incubation, the images of the gap between the scratch was imaged and compared. 


\section{Cellular Physiology Cell Physiol Biochem 2018;47:1925-1935

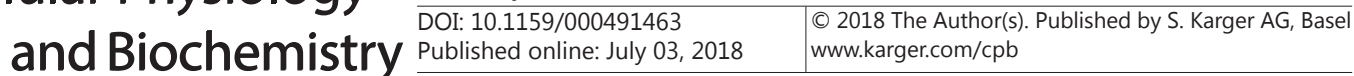 \\ Li et al.: Activator Protein-2 $\beta$ Promotes Tumor Growth}

Transwell assay

The lower chambers of 24 -well chemotaxis chambers (Corning, CA, USA) were filled with $500 \mu$ l medium containing $20 \%$ fetal bovine serum. The cells treated were added into the upper chambers coated with a mixture of serum-free medium and matrigel (4:1; BD Biosciences, CA, USA) and continuously incubated for 60 hours. Then the membrane were fixed in methyl alcohol for $10 \mathrm{~min}$ at RT, stained with crystal violet for 10 min, washed 3 times with PBS and dried off. The invaded cells were finally photographed with digital camera.

\section{Animal studies}

Animal experiments were performed in accordance with the National Institute of Health Guide for the Care and Use of Laboratory Animals, with the approval of the Animal Research Committee of Dalian Medical University. Female Balb/c nude mice at the age of 4 to 6 weeks were used. The MDA-MB-231 cells with stable knockdown or overexpression of AP- $2 \beta$ or their respective control cells $\left(3 \times 10^{6}\right)$ were injected subcutaneously into the left flank of each mouse. The tumor growth was monitored with the tumor size measurement once every four days since the tenth day after cell injection. The tumor volumes were calculated as following: $\mathrm{V}=($ width $2 \times$ length $) / 2$, and the tumors were weighted after the mice were sacrificed.

\section{Statistical analyses}

All the data are presented as mean \pm SD. A Student $t$ test was performed to compare data among different groups. $\mathrm{P} \leq 0.05$ was considered statistically significant. The correlation between AP- $2 \beta$ expression and categorical variables was compared by Pearson chi-squared test. Survival curves were calculated using the Kaplan Meier method and compared using Log-rank test. Multivariate analysis was performed using the Cox regression model. Data was analyzed by the SPSS 20 software.

\section{Results}

\section{AP-2 $\beta$ was highly expressed in breast cancer cells and tumor tissues}

The expression of AP- $2 \beta$ was first detected in breast cancer cells. Western blot analysis indicated AP-2 $\beta$ was expressed in various breast cancer cell lines (Fig. 1A). We further tested its expression and localization in breast cancer tissues from 140 patients with breast cancer using immunohistochemical (IHC) staining. High AP-2 $\beta$ expression was exhibited in $71(50.7 \%)$ patients. The representative staining images was shown in Fig. 1B. The main nuclear localization of $\mathrm{AP}-2 \beta$ in tumor cells was found based on HE staining and IHC staining. Interestingly, synchronous accumulation in nucleus and cytoplasm of AP- $2 \beta$ was shown in the patients with high AP-2 $\beta$ expression, and only sporadic nucleus staining but not cytoplasmic distribution was found in the patients with low AP-2 $\beta$ expression. Additionally, we also analyzed the Oncomine database and found a statistically significant

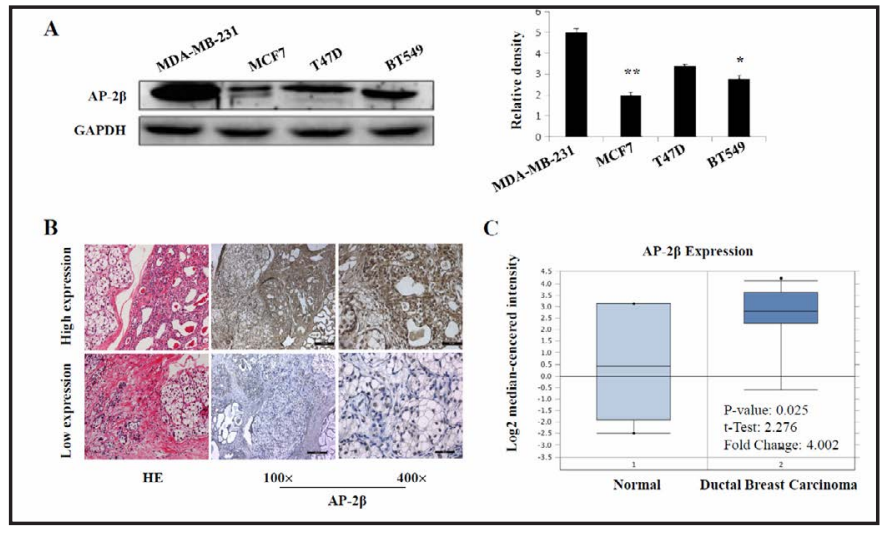

Fig. 1. AP- $2 \beta$ was highly expressed in breast cancer cells and tumor tissues. (A) The expression of AP- $2 \beta$ protein in various breast cancer cell lines. The density of the AP- $2 \beta$ protein bands was quantified relative to the GAPDH protein bands. (B) The expression of AP- $2 \beta$ protein in tumor tissues from patients with breast cancer by immunohistochemistry analysis and the representative staining images were shown. (C) Analysis of AP- $2 \beta$ expression in breast cancer from Oncomine database. The data were presented as the mean $\pm \mathrm{SD}$ from three independent experiments $\left({ }^{*} \mathrm{p}<0.05\right.$, $* * \mathrm{p}<0.01)$. 
Fig. 2. Kaplan-Meier survival curves for overall survival in 140 patients with breast cancer. (A) High-expression of AP-2 $\beta$ was associated with worse overall survival $(\mathrm{p}=0.001)$ in breast cancer. (B) The patients with elevated TNM staging $(\mathrm{p}<0.001)$ had shorter lifetime.

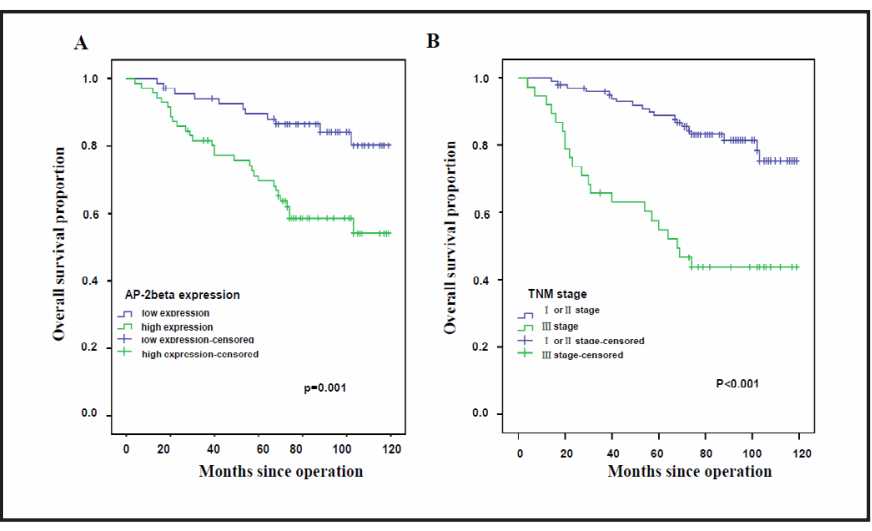

overexpression of AP-2 $\beta$ in ductal breast carcinoma compared to the normal tissues ( $p=0.015$ ) (Fig. 1C). These results demonstrated the overexpression of AP$2 \beta$ in breast cancer and also suggested the potential of its high expression involved in the development of breast cancer.

High expression of AP-2 $\beta$ predicted poor prognosis and low survival rate in patients with breast cancer

To further verify the significance of AP-2 $\beta$ expression in breast cancer development, we investigated the association between AP- $2 \beta$ expression and clinicopathological characteristics. $\mathrm{AP}-2 \beta$ expression was analyzed using IHC staining based on tissue microarray from 140 patients, among which $121(86.4 \%)$ were invasive ductal type, $3(2.1 \%)$ were invasive lobular type, 2 (1.4\%) were invasive mucinous type and $1(0.7 \%)$ was intraductal type, and the rest were the mixed type of invading lobular carcinoma combined with mucinous carcinoma $(\mathrm{n}=4)$ or micro papillary carcinoma $(\mathrm{n}=9)$. As shown in Table 1, the expression of AP-2 $\beta$ was significantly associated with tumor size $(\mathrm{p}=0.014)$, lymph node metastasis $(\mathrm{p}=0.007)$ and TNM stage $(p=0.013)$. The univariate survival analysis showed that differentiation $(p=0.026)$, tumor size $(p=0.001)$, lymph node metastasis $(\mathrm{p}=0.029)$, AP- $2 \beta$ expression $(\mathrm{p}=0.001)$ and TNM staging $(\mathrm{p}<0.001)$ was significantly associated with survival outcome, but age, pathological classification and locus position were not (all $p>0.5$, Table 2). Furthermore, a multivariate analysis, including differentiation, tumor size, lymph node metastasis, AP-2 $\beta$
Table 1. Relations between the AP- $2 \beta$ expression and clinicopathologic characteristics in 140 breast cancer

\begin{tabular}{|c|c|c|c|}
\hline \multirow{2}{*}{ Variable } & \multicolumn{2}{|c|}{ AP-2 $\beta$ expression } & \multirow[t]{2}{*}{ P-value } \\
\hline & Low & High (\%) & \\
\hline Overall & 69 & $71(50.7)$ & \\
\hline Age & & & 0.994 \\
\hline$\leq 57$ & 36 & $37(50.7)$ & \\
\hline$>57$ & 33 & $34(50.7)$ & \\
\hline Pathological classification & & & 0.348 \\
\hline Invasive ductal type & 57 & $64(52.9)$ & \\
\hline Invasive lobular type & 3 & $0(0)$ & \\
\hline Invasive mucinous type & 1 & $1(50.0)$ & \\
\hline Intraductal type & 1 & $0(0)$ & \\
\hline Others & 7 & $6(46.2)$ & \\
\hline Differentiation & & & 0.156 \\
\hline Well & 2 & $2(50.0)$ & \\
\hline Moderate & 56 & $48(46.2)$ & \\
\hline Poor & 11 & $21(65.6)$ & \\
\hline Locus position & & & 0.059 \\
\hline Right & 44 & $43(43.6)$ & \\
\hline Left & 25 & $37(59.7)$ & \\
\hline Tumor size & & & 0.014 \\
\hline $\mathrm{T} 1 \leq 2 \mathrm{~cm}$ & 24 & $15(38.5)$ & \\
\hline $\mathrm{T} 2>2 \mathrm{~cm}, \leq 5 \mathrm{~cm}$ & 42 & $42(50.0)$ & \\
\hline $\mathrm{T} 3>5 \mathrm{~cm}$ & 3 & $12(80.0)$ & \\
\hline $\mathrm{T} 4$ & 0 & $2(100.0)$ & \\
\hline Lymph node metastasis & & & 0.07 \\
\hline With & 25 & $42(62.7)$ & \\
\hline Without & 44 & $29(39.7)$ & \\
\hline TNM staging & & & 0.013 \\
\hline Stage I and 0 & 14 & $11(44.0)$ & \\
\hline Stage II & 44 & $33(42.9)$ & \\
\hline Stage III & 11 & $27(71.1)$ & \\
\hline
\end{tabular}


expression and TNM staging, was performed to explore the independent predictor for the prognosis of patients in these 140 individuals. As shown in Table 3, both high rank TMN staging (HR: 3.323, 95\%CI: 1.760-6.276, p <0.001) and high AP-2 $\beta$ expression (HR: 2.410, 95\%CI: $1.182-4.4914, \mathrm{p}=0.016)$ were displayed as an independent risk factor of overall survival. In addition, Kaplan-Meier survival curves indicated the 10-year overall survival (10-OS) of breast cancer patients with high AP- $2 \beta$ expression was shorter than the ones with lower expression (10-OS: $54.1 \%$ vs $80.2 \%, p=0.001$ ) (Fig. $2 \mathrm{~A}$ ). Similarly, 10-OS of breast cancer patients with high TNM staging was significantly shorter than the ones with low TNM staging (Fig. 2B).

Knockdown of AP-2 $\beta$ suppressed the growth and metastasis of breast cancer cells

We next assessed the role of AP- $2 \beta$ in breast cancer progression by evaluating its effects on cell growth and metastasis. The breast cancer MDA-MB-231, T47D and BT549 cells were transfected with AP- $2 \beta$ specific shRNA. At 48 hours after transfection, AP- $2 \beta$ expression was detected and significantly inhibited at mRNA and protein levels (Fig. 3A). Furthermore, the cell viability, colony formation ability, cell migration and invasiveness were tested respectively. As shown in Fig. 3B and 3C, the silencing of AP- $2 \beta$ expression resulted in the significant suppression of tumor cell viability and colony formation ability, compared to those transfected with the control shRNA. Consistent with this, its silencing also resulted in the downregulated cell migration and invasive capability, compared to those untreated or transfected with the control shRNA (Fig. 3D, 3E). All these results together suggested the regulation of AP- $2 \beta$ on the progression of breast cancer cell growth. Next, we analyzed the signaling pathways activated by AP- $2 \beta$ in its regulation on tumor cell growth. We initially examined the effects of AP-2 $\beta$ knockdown on MAPK, MMPs, p75 and STAT3 signaling pathways, given their key role in mediating tumor progression. As shown in Fig. $3 \mathrm{~F}, \mathrm{AP}-2 \beta$ knockdown led to marked reduction in the levels of p75, MMP2, MMP9, C-Jun, STAT3 and the phosphorylated ERK1/2. On the contrary, the overexpression of AP- $2 \beta$ in breast cancer cells (Fig. 3G) significantly induced the expression of the proteins above, compared to the control vector (GFP plasmids)-treated cells (Fig. $3 \mathrm{H}$ ), demonstrating that the tumor-
Table 2. Patients' univariate analysis of overall survival

\begin{tabular}{|c|c|c|c|}
\hline Characteristics & HR $(95 \% \mathrm{Cl})$ & $\begin{array}{l}\text { 10-Year } \\
\text { OS Rate \% }\end{array}$ & P-value \\
\hline Age & & & 0.964 \\
\hline$\leq 57$ & 1 & 68.7 & \\
\hline$>57$ & $0.986(0.530-1.835)$ & 63.6 & \\
\hline Pathological classification & & & 0.318 \\
\hline type ${ }^{\text {Non-invasive lobular }}$ & 1 & 49.4 & \\
\hline Invasive ductal type & $1.511(0.667-3.421)$ & 69.6 & \\
\hline Differentiation & & & 0.026 \\
\hline Poor & 1 & 55.1 & \\
\hline Moderate & $0.456(0.237-0.879)$ & 71.2 & \\
\hline Well & $0.482(0.063-3.671)$ & 66.7 & \\
\hline Locus position & & & 0.850 \\
\hline Right & 1 & 65.1 & \\
\hline Left & $1.020(0.547-1.902)$ & 69.3 & \\
\hline T size & & & 0.001 \\
\hline $\mathrm{T} 1$ and $\mathrm{T} 2$ & 1 & 70.5 & \\
\hline $\mathrm{T} 3$ and $\mathrm{T} 4$ & $3.359(1.589-7.101)$ & 42.0 & \\
\hline Lymph node metastasis & & & 0.029 \\
\hline Without & 1 & 59.5 & \\
\hline With & $2.016(1.061-3.832)$ & 73.4 & \\
\hline TNM & & & $<0.001$ \\
\hline Stage I and II & 1 & 75.3 & \\
\hline Stage III & $4.006(2.149-7.465)$ & 43.7 & \\
\hline AP- $2 \beta$ expression & & & 0.001 \\
\hline Low & 1 & 80.2 & \\
\hline High & $3.061(1.527-6.135)$ & 54.1 & \\
\hline
\end{tabular}

Table 3. Multivariate analysis of overall survival

\begin{tabular}{llll}
\hline Variable & Hazard Ratio. & $\mathbf{9 5 \%}$ CI & P-value \\
\hline Differentiation & & & 0.147 \\
Poor & 1 & & \\
Moderate & 0.515 & $0.264-1.004$ & \\
Well & 0.828 & $0.106-6.495$ & \\
T size & & & 0.194 \\
T1d T2 & 1 & & \\
T3 and T4 & 1.704 & $0.762-3.812$ & \\
Lymph node metastasis & & & 0.732 \\
With & 1 & & \\
Without & 0.847 & $0.338-2.122$ & \\
TNM & & & \\
Stage I and II & 1 & & \\
Stage III & 3.323 & $1.760-6.276$ & \\
AP-2 2 expression & & & 0.016 \\
Low & 1 & & \\
High & 2.410 & &
\end{tabular}




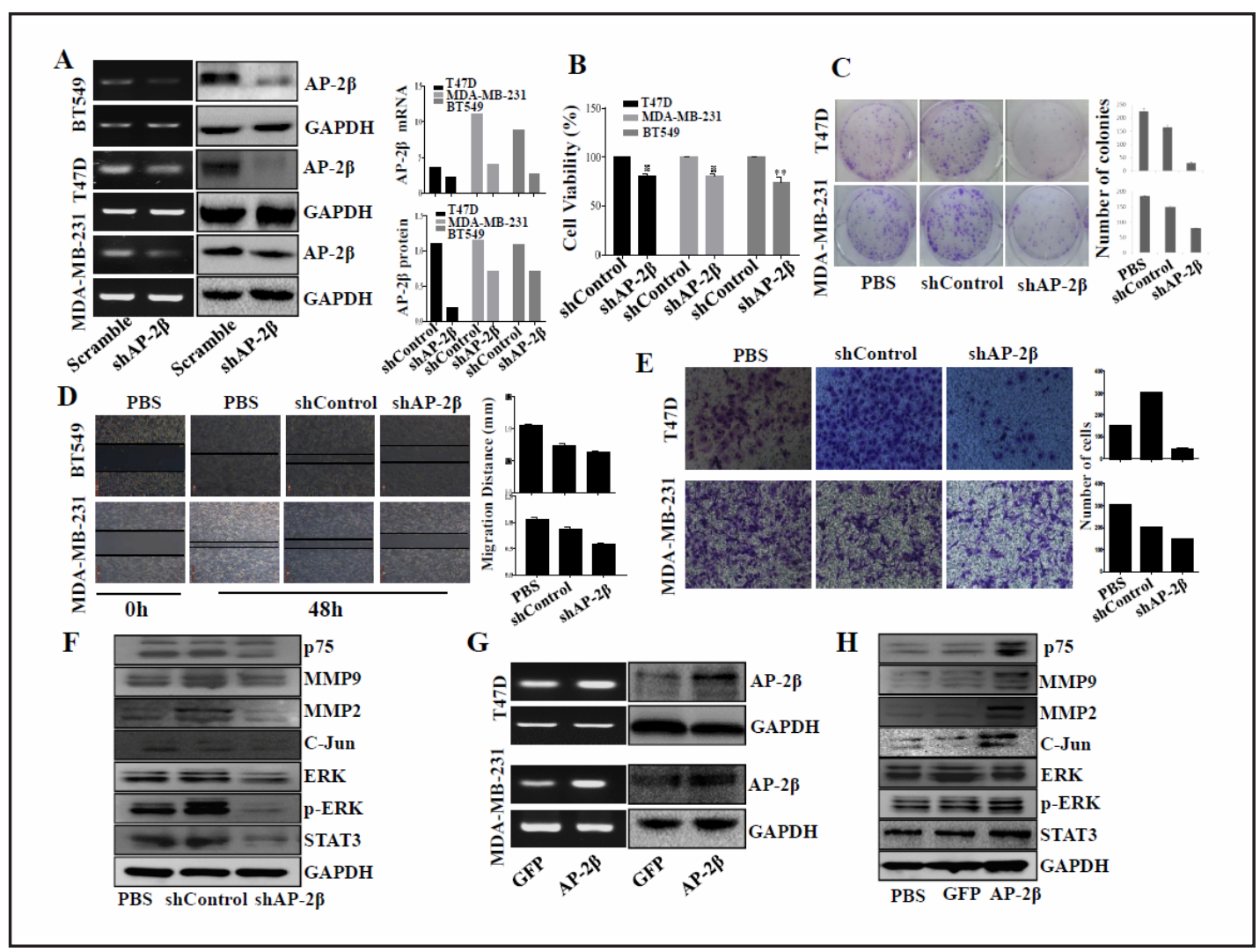

Fig. 3. AP- $2 \beta$ regulated the growth, metastasis and the expressions of proteins involved in tumor progression in breast cancer cells. Breast cancer cells MDA-MB-231, T47D and BT549 were transfected with AP-2 $\beta$ shRNA or control shRNA for 48 hours, and then (A) AP- $2 \beta$ expression was analyzed by RT-PCR and Western blot. The quantification assay of the expression level was performed. (B) Cell viability was measured by MTT assay. (C) Colony formation assay of MDA-MB-231 and T47D cells following AP-2 $\beta$ knockdown. The quantification assay of the colony number was also performed. (D) Cell migration ability was measured by scratch assay in MDA-MB-231 and BT549 cells following AP-2 $\beta$ knockdown. The quantification assay of the migration distance was also performed. (E) Cell invasive ability was detected by transwell model in breast cancer cell lines T47D and MDA-MB-231 following AP-2 $\beta$ knockdown. (F) The levels of p75, MMP2, MMP9, C-Jun, STAT3 and the phosphorylated ERK1/2 were detected by Western blot in MDA-MB-231 cells following AP-2 $\beta$ knockdown. (G) MDA-MB-231 and T47D cells were transfected with AP-2 $\beta$ overexpressing plasmids or GFP plasmids as control for 48 hours, and then AP-2 $\beta$ expression was analyzed by RT-PCR and Western blot. (H) The levels of p75, MMP2, MMP9, C-Jun, STAT3 and the phosphorylated ERK1/2 were detected by Western blot in MDA-MB-231 cells following AP-2 $\beta$ overexpression. The data were repeated three times and presented as the mean $\pm \mathrm{SD}\left({ }^{*} \mathrm{p}<0.05,{ }^{* *} \mathrm{p}<0.01\right)$.

promoting effect of AP-2 $\beta$ was partially realized via activating the MAPK/STAT3, MMPs and p75 signaling pathways in breast cancer cells.

AP-2 $\beta$ regulated tumor growth in a mouse model with xenografts of human breast cancer

We next validated the AP-2 $\beta$-mediated regulation of tumor growth in a mouse model with xenografts of human breast cancer in vivo. The MDA-MB-231 cells with stable knockdown or overexpression of AP-2 $\beta$ were respectively established by transfecting these cells with lentiviruses encapsulating AP-2 $\beta$ specific shRNAs or its overexpressing plasmids. The cells with different expression of AP- $2 \beta$ or control shRNA or control plasmids (GFP) were subcutaneously injected into nude mice individually and the tumor growth was observed. As shown in Fig. 4A-4D, knockdown of AP-2 $\beta$ significantly suppressed tumor growth. Inversely, its over-expression effectively promoted the in vivo tumor progression. The knockdown or

\section{KARGER}




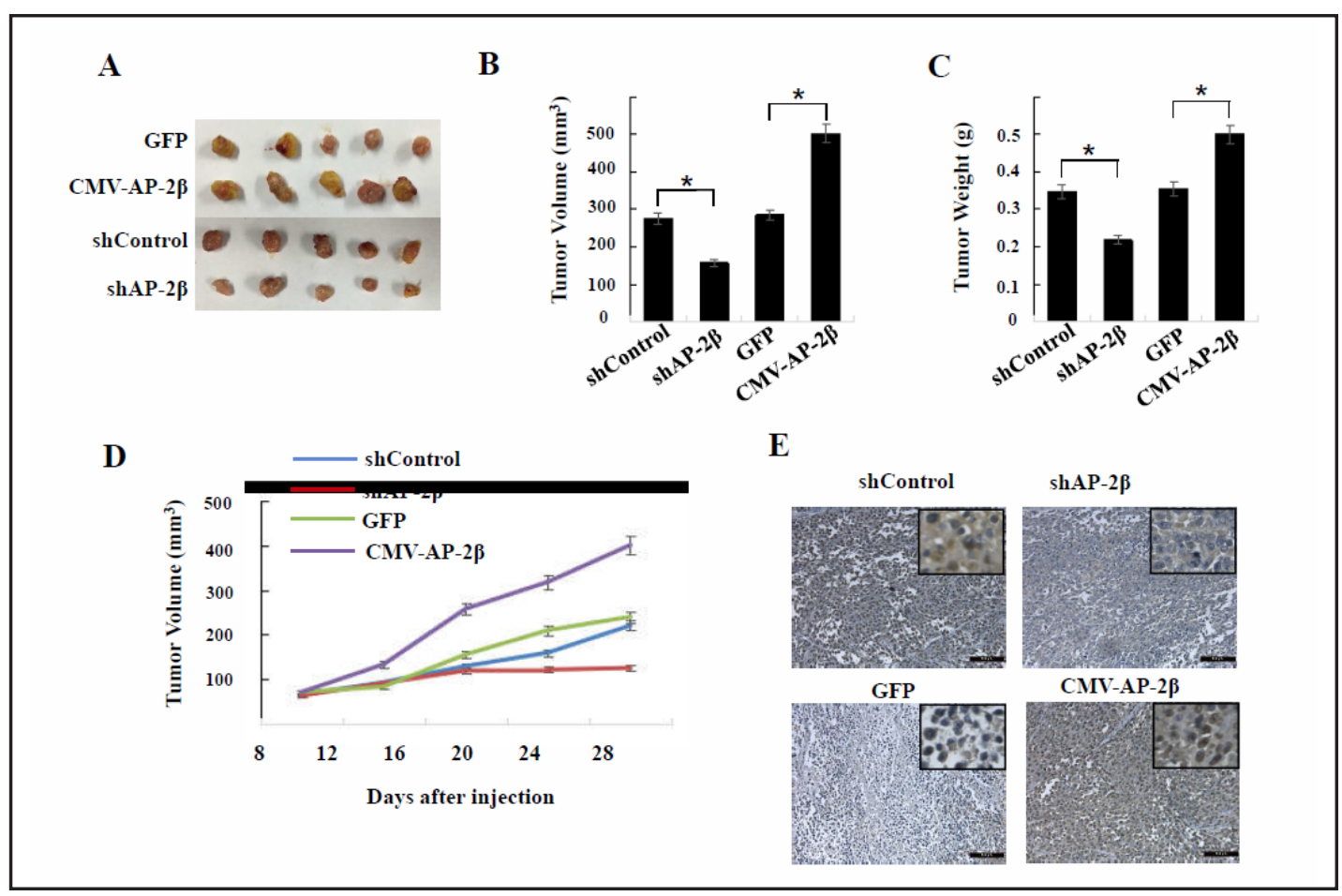

Fig. 4. AP- $2 \beta$ promoted tumorigenesis and progression in a human breast cancer mouse model in vivo. The MDA-MB-231 cells with stable knockdown or overexpression of AP-2 $\beta$ were subcutaneously injected into nude mice individually and the tumor growth was observed. (A) The morphology of tumor xenografts in each nude mouse from different groups. (B) Tumor volume of nude mice from each group was measured and calculated at 28 days when the mice were sacrificed. (C) Tumor weight of nude mice from each group was measured also at 28 days when the mice were sacrificed, ${ }^{*}, \mathrm{p}<0.05$. (D) Tumor volume of nude mice from each group was measured and calculated at different days after tumors were formed. (E) The expression levels of AP-2 $\beta$ from tumor xenografts in each group of nude mice by immunohistochemistry assay.

overexpression of AP-2 $\beta$ in the xenografts were respectively detected and confirmed through IHC analysis (Fig. 4E). Combined with the in vitro study, these data indicated the regulation of $\mathrm{AP}-2 \beta$ on tumor growth in breast cancer development.

\section{Discussion}

Given the involvement of AP-2 transcription factor family in the regulation of many biological functions, including cell proliferation, differentiation, apoptosis and carcinogenesis [7-10, 23-26], the function and molecular mechanisms of each member in this family deserves to be better investigated in human diseases, especially in cancer initiation and development. However, to date, most studies focused on AP- $2 \alpha$ and AP- $2 \gamma$, and the reports about the other three family members, $\mathrm{AP}-2 \beta, \mathrm{AP}-2 \delta$, and $\mathrm{AP}-2 \varepsilon$, were very rare. Our previous studies demonstrated the tumorigenic role of AP- $2 \beta$ in lung cancer by transcriptionally regulating human telomerase reverses transcriptase [22]. To expand this point, it might also play the same role in other cancer types, including breast cancer. Defining the possible candidate target driving breast cancer is also critical for the development of new therapeutic strategies for the advanced form of the disease. Here we demonstrate that AP- $2 \beta$ was highly expressed in breast cancer cells and tumor tissues. AP- $2 \beta$ knockdown obviously inhibited breast cancer cell growth and metastasis in vitro and tumor progression in vivo. To the best of our knowledge, it might firstly report the elevated expression of AP- $2 \beta$ and its tumor-promoting function in breast cancer survival. 
Our analysis from the clinical tissue samples based on 140 patients with different breast cancer types, most of which were invasive phenotypes, similarly illustrated the high expression of AP- $2 \beta$ and its significant association with tumor size, lymph node metastasis and TNM stage, which are the frequently used risk factors of prognosis in different tumors [27]. The univariate analysis showed that AP- $2 \beta$ expression was associated with survival outcome in the enrolled patients by log-rank test $(p=0.001)$. Cox regression analysis verified high AP-2 $\beta$ expression as an independent risk factor of overall survival. Combined with the in vitro study and mouse model study, our findings fully suggest the tumor-promoting role of AP- $2 \beta$ and its prediction for the poor prognosis of patients with breast cancer. Interestingly, we also found AP- $2 \beta$ synchronously accumulated in nucleus and cytoplasm, and only sporadically distributed in nucleus but not cytoplasm in patients with low AP- $2 \beta$ expression, indicating the expression activation and subsequent nuclear translocation of AP- $2 \beta$ might happen during breast cancer development, especially in the EMT process. However, no information about the subtypes of breast cancer patients, especially triple negative patients, and the received treatment of the patients was provided in the tissue microarrays used in the study. To determine whether the expression of AP- $2 \beta$ is associated with subtypes of breast cancer patients and whether treatment of the patients may alter the expression of AP- $2 \beta$ and discover the relationship among treatment, specific gene expression and cancer progression, the information on the subtypes of breast cancer patients and the treatment information for the tumor tissue samples from the patients are needed in the future study.

In addition, in our study, the changed activity of MAPK signaling pathway was observed upon AP- $2 \beta$ knockdown or overexpression in breast cancer cells accompanied by the downregulated or up-regulated p-ERK, c-jun, STAT3 and MMPs accordingly. Therefore, we deduce MEK/ERK/c-jun and MEK/STAT3/MMPs signaling might function as the key downstream effectors to mediate the tumor-promoting role of $\mathrm{AP}-2 \beta$ in breast cancer progression. Moreover, considering the function of AP- $2 \beta$ itself as transcriptional factor [28-32], most likely, it plays its oncogenic role in breast cancer development via elevating gene expression transcriptionally. Thus, a certain key protein molecule transcriptionally regulated by AP$2 \beta$ possibly exists as the direct down-stream target of AP- $2 \beta$ to monitor MAPK signaling pathway and further to mediate the oncogenic role of AP- $2 \beta$. The transcriptome profiling of tumor cells with high or low AP-2 $\beta$ expression might reveal such and also its real downstream targets, and might not limit to only one but many targets. These targets might also synergize with each other to co-mediate the tumor-promoting effect of AP- $2 \beta$ in breast cancer cells. However, all the hypothesis and mechanisms underlying the activation of AP- $2 \beta$ in advanced breast cancer are yet to be elucidated.

In summary, we have provided functional evidence that AP- $2 \beta$ drives breast cancer progression in vitro and in vivo. High expression of AP- $2 \beta$ significantly associates with tumor size, lymph node metastasis, and TNM stage, and functionalizes as an independent risk factor of overall survival in patients with breast cancer. All the results suggest that overexpression of AP- $2 \beta$ may serve as a biomarker to predict the poor prognosis and as a potential therapeutic target for patients suffering breast cancer, especially those with high malignant type.

\section{Acknowledgements}

This work was supported by the funds from the National Natural Science Foundation of China (81372133, 81473452, 81572706, 81472178), the funds from the National Natural Science Foundation of Liaoning Province (2015020661), the Scientific Research Project from the Education Department of Liaoning Province, China (L2015142).

\section{Disclosure Statement}

We declare that we have no competing financial interests. We have no Disclosure Statements. 


\section{Cellular Physiology Cell Physiol Biochem 2018;47:1925-1935 \begin{tabular}{l|l} 
DOI: 10.1159/000491463 & $\begin{array}{l}\text { O } 2018 \text { The Author(s). Published by S. Karger AG, Basel } \\
\text { www.karger.com/cpb }\end{array}$
\end{tabular}}

Li et al.: Activator Protein-2 $\beta$ Promotes Tumor Growth

\section{References}

1 Simone V, D’Avenia M, Argentiero A, Felici C, Rizzo FM, De Pergola G, Silvestris F: Obesity and breast cancer: Molecular interconnections and potential clinical applications. Oncologist 2016;21:404-417.

-2 Siegel RL, Fedewa SA, Miller KD, Goding-Sauer A, Pinheiro PS, Martinez-Tyson D, Jemal A: Cancer statistics for hispanics/latinos, 2015. CA Cancer J Clin 2015;65:457-480.

-3 Ferlay J, Steliarova-Foucher E, Lortet-Tieulent J, Rosso S, Coebergh JW, Comber H, Forman D, Bray F: Cancer incidence and mortality patterns in europe: Estimates for 40 countries in 2012. Eur J Cancer 2013;49:1374-1403.

-4 Schonberg MA, Marcantonio ER, Li D, Silliman RA, Ngo L, McCarthy EP: Breast cancer among the oldest old: Tumor characteristics, treatment choices, and survival. J Clin Oncol 2010;28:2038-2045.

5 Braunstein LZ, Taghian AG: Molecular phenotype, multigene assays, and the locoregional management of breast cancer. Semin Radiat Oncol 2016;26:9-16.

6 Malhotra GK, Zhao X, Band H, Band V: Histological, molecular and functional subtypes of breast cancers. Cancer Biol Ther 2010;10:955-960.

7 Eckert D, Buhl S, Weber S, Jager R, Schorle H: The ap-2 family of transcription factors. Genome Biol 2005;6:246.

-8 Hilger-Eversheim K, Moser M, Schorle H, Buettner R: Regulatory roles of ap-2 transcription factors in vertebrate development, apoptosis and cell-cycle control. Gene 2000;260:1-12.

-9 Li Q Dashwood RH: Activator protein 2alpha associates with adenomatous polyposis coli/beta-catenin and inhibits beta-catenin/t-cell factor transcriptional activity in colorectal cancer cells. J Biol Chem 2004;279:45669-45675.

-10 Turner BC, Zhang J, Gumbs AA, Maher MG, Kaplan L, Carter D, Glazer PM, Hurst HC, Haffty BG, Williams T: Expression of ap-2 transcription factors in human breast cancer correlates with the regulation of multiple growth factor signalling pathways. Cancer Res 1998;58:5466-5472.

-11 Ruiz M, Pettaway C, Song R, Stoeltzing O, Ellis L, Bar-Eli M: Activator protein 2alpha inhibits tumorigenicity and represses vascular endothelial growth factor transcription in prostate cancer cells. Cancer Res 2004;64:631-638.

12 Bar-Eli M: Gene regulation in melanoma progression by the ap-2 transcription factor. Pigment Cell Res 2001;14:78-85.

13 Anttila MA, Kellokoski JK, Moisio KI, Mitchell PJ, Saarikoski S, Syrjanen K, Kosma VM: Expression of transcription factor ap-2alpha predicts survival in epithelial ovarian cancer. Br J Cancer 2000;82:19741983.

14 Heimberger AB, McGary EC, Suki D, Ruiz M, Wang H, Fuller GN, Bar-Eli M: Loss of the ap-2alpha transcription factor is associated with the grade of human gliomas. Clin Cancer Res 2005;11:267-272.

15 Pauls K, Jager R, Weber S, Wardelmann E, Koch A, Buttner R, Schorle H: Transcription factor ap-2gamma, a novel marker of gonocytes and seminomatous germ cell tumors. Int J Cancer 2005;115:470-477.

-16 Hoei-Hansen CE, Rajpert-De Meyts E, Carlsen E, Almstrup K, Leffers H, Skakkebaek NE: A subfertile patient diagnosed with testicular carcinoma in situ by immunocytological staining for ap-2gamma in semen samples: Hum Reprod 2005;20:579-582.

-17 Werling U, Schorle H: Transcription factor gene ap-2 gamma essential for early murine development. Mol Cell Biol 2002;22:3149-3156.

-18 Friedrichs N, Jager R, Paggen E, Rudlowski C, Merkelbach-Bruse S, Schorle H, Buettner R: Distinct spatial expression patterns of ap-2alpha and ap-2gamma in non-neoplastic human breast and breast cancer. Mod Pathol 2005;18:431-438.

19 Gee JM, Robertson JF, Ellis IO, Nicholson RI, Hurst HC: Immunohistochemical analysis reveals a tumour suppressor-like role for the transcription factor ap-2 in invasive breast cancer. J Pathol 1999;189:514-520.

20 Korkola JE, DeVries S, Fridlyand J, Hwang ES, Estep AL, Chen YY, Chew KL, Dairkee SH, Jensen RM, Waldman FM: Differentiation of lobular versus ductal breast carcinomas by expression microarray analysis. Cancer Res 2003;63:7167-7175.

21 Hu X, Wang L, Sun W, Xiao L, Wu Y, Zhuo Y, Nie D, Zhou J, Zhang J: Ap-2beta enhances p53-mediated transcription of the alphab-crystallin gene through stabilizing p53. Mol Biol Rep 2012;39:209-214. 


\section{Cellular Physiology Cell Physiol Biochem 2018;47:1925-1935 \begin{tabular}{l|l} 
DOI: 10.1159/000491463 & $\begin{array}{l}\text { O } 2018 \text { The Author(s). Published by S. Karger AG, Basel } \\
\text { www.karger.com/cpb }\end{array}$
\end{tabular} \\ Li et al.: Activator Protein-2 $\beta$ Promotes Tumor Growth}

-22 Deng WG, Jayachandran G, Wu G, Xu K, Roth JA, Ji L: Tumor-specific activation of human telomerase reverses transcriptase promoter activity by activating enhancer-binding protein-2beta in human lung cancer cells. J Biol Chem 2007;282:26460-26470.

23 Wajapeyee N, Britto R, Ravishankar HM, Somasundaram K: Apoptosis induction by activator protein 2alpha involves transcriptional repression of bcl-2. J Biol Chem 2006;281:16207-16219.

24 Wajapeyee N, Somasundaram K: Cell cycle arrest and apoptosis induction by activator protein 2alpha (ap-2alpha) and the role of p53 and p21waf1/cip1 in ap-2alpha-mediated growth inhibition. J Biol Chem 2003;278:52093-52101.

25 Campillos M, Garcia MA, Valdivieso F, Vazquez J: Transcriptional activation by ap-2alpha is modulated by the oncogene dek. Nucleic Acids Res 2003;31:1571-1575.

-26 McPherson LA, Loktev AV, Weigel RJ: Tumor suppressor activity of ap2alpha mediated through a direct interaction with p53. J Biol Chem 2002;277:45028-45033.

27 Fitzgibbons PL, Page DL, Weaver D, Thor AD, Allred DC, Clark GM, Ruby SG, O'Malley F, Simpson JF, Connolly JL, Hayes DF, Edge SB, Lichter A, Schnitt SJ: Prognostic factors in breast cancer. College of american pathologists consensus statement 1999. Arch Pathol Lab Med 2000;124:966-978.

28 Seki R, Kitajima K, Matsubara H, Suzuki T, Saito D, Yokoyama H, Tamura K: Ap-2beta is a transcriptional regulator for determination of digit length in tetrapods. Dev Biol 2015;407:75-89.

29 Fu L, Chen W, Guo W, Wang J, Tian Y, Shi D, Zhang X, Qiu H, Xiao X, Kang T, Huang W, Wang S, Deng W: Berberine targets ap-2/htert, nf-kappab/cox-2, hif-1alpha/vegf and cytochrome-c/caspase signaling to suppress human cancer cell growth. PloS One 2013;8:e69240.

-30 Rossello XS, Igbavboa U, Weisman GA, Sun GY, Wood WG: Ap-2beta regulates amyloid beta-protein stimulation of apolipoprotein e transcription in astrocytes. Brain Res 2012;1444:87-95.

-31 Kondo M, Ugi S, Morino K, Fuke T, Obata T, Yoshizaki T, Nishio Y, Maeda S, Kashiwagi A, Maegawa H: Postprandial activation of protein kinase cmicro regulates the expression of adipocytokines via the transcription factor ap-2beta. Int J Mol Med 2011;28:95-100.

-32 Hong SJ, Huh YH, Leung A, Choi HJ, Ding Y, Kang UJ, Yoo SH, Buettner R, Kim KS: Transcription factor ap2 beta regulates the neurotransmitter phenotype and maturation of chromaffin cells. Mol Cell Neurosci 2011;46:245-251. 